\title{
Mind-Body Relationship Based on Modern Neuroscience Research and Buddhist Meditation.
}

\author{
Ven. Polgolle Kusaladhamma \\ Lecturer; Department of Buddhist Studies, \\ Sri Lanka International Buddhist Academy, \\ Pallekele, Kandy, Sri Lanka.
}

\begin{abstract}
Neuroscientists and genetics started a new era in human history. Neuroscience is a modern science and it developed after 1950. Scientific study of the body investigates how the messages in transit from the senses to the brain and make decisions and feelings. The neuron system of the body is the coordinator of the transiting information in the body. Neurons are cells specialized for communication. The Majjhima Nikāya mentions the process of sense perception. Depending on the visual organ and the visible objects, it arises visual consciousness; the meeting together of these three is contact; because of contact arises feeling. What one feels, one perceives; what one perceives; one reason about; what one reason about, one is obsessed with. What one is obsessed with, due to that, concepts characterized by such obsessed perceptions assail him in regard to visible objects cognizable by the visual organ, belonging to the past, the future and the present. Buddhism accepts the testimony as a source of knowledge. Buddhism recognizes experiences, both sensory and extrasensory and reasoning or inference based on experience as sources of knowledge. Scientific method of finding new knowledge and Buddhist view point of finding new knowledge similar to each other in this contest. The modern neuroscientist explores about the brain mechanisms pertain of attention and emotion. The Buddhist Meditation answers to physical and mental problems and boost the physical and mental strength. The Buddhist Meditation and neuroscientist both do an experiment in the similar field. By these interdisciplinary study can understand the mechanism of the brain and the utility of the Meditation boost the processes of the brain. The modern scientific experiment described the negative effects of stress on the body. The relaxation is linked to higher levels of feel-good chemicals such as serotonin and to the growth hormone which repairs cells and tissue, lowering heart rate, boosting immunity and strengthening the body.
\end{abstract}

Key words: Samatha Meditation, Vipassnā Meditation, Brain Plasticity, Brain Mechanism, CNS, PNS, ICD

\section{INTRODUCTION}

Meditation practices mainly focus to train the mind for overcoming the suffering, especially negative forces in emotions that create mental unrest, unhappiness, fear, and frustration etc. that bring more problems and suffering. The negative emotions bring not only mental unrest, but also it is detrimental to physical health. The positive states of the mind bring inner strength, mental fortitude and, due to that beneficial to the physical health. The modern neuroscientist also explore about the brain mechanisms pertain of attention and emotion. This paper mainly focuses to find out "Mind-Body Relationship Based on Neuroscience and Meditation".

Neuroscientists and genetics started a new era in human history. Neuroscience is a modern science and it developed after 1950. Scientific study on the body investigates how the messages transit from the senses to the brain and make decisions and feelings. The neuron 
system of the body is the coordinator of the transiting information in the body. Neurons are cells specialized for communication. Majjhima Nikāya mentions the process of sense perception.

"Depending on the visual organ and the visible objects, arises visual consciousness; the meeting together of these three is contact; because of contact arises feeling. What one feels, one perceives; what one perceives; one reasons about; what one reasons about, one is obsessed with. What one is obsessed with, due to that, concepts characterized by such obsessed perceptions assail him in regard to visible objects cognizable by the visual organ, belonging to the past, the future and the present"

Buddhism accept the testimony as source of knowledge. Buddhism recognize experiences, both sensory and extrasensory and reasoning or inference based on experience as sources of knowledge. Scientific method of finding new knowledge and Buddhist view point of finding new knowledge similar to each other in this contest.

\section{RESEARCH METHODOLOGY}

This article uses research methods such as records of the scientific experiments, analysis of documents, nonparticipant direct observation, mass observation, personal interview, group interview, and case study and life history etc.

\section{RESULT AND DISCUSSION}

Based on the Current information, during meditation our brainwaves usually start with the Beta; Thinking state. Then to Alpha; more relaxed, mentally and physically. After followed by the Theta state; Vivid visualization, great inspiration, profound, creativity and exceptional insight. From Theta to Delta Waves; Unconsciousness or dreamless sleep. Gamma Waves are recently discovered and appear in continued mediation; Feeling of bliss.

The experiments show that Meditation can slow or speed metabolism by more than $60 \%$ and raise body temperature by much as $8 \mathrm{C}^{0}$. Short time period meditation practice makes people calm, less stressed, and relax. 20 minutes of Meditation leads to physical changes such as reduced blood pressure, lower the heart rate, deeper and calmer breathing, lower risk of heart attack, and treatment for chronic and acute pain.

Neurobiologist believed human brain can change during infancy and childhood until 1960. The brain plasticity means brain's ability of changing and adapt as a result of experiences. Modern neurobiologists believe the brain continues to create new neural pathways, learn new information and create new memories according to neuron plasticity. The plasticity occur during the lifetime but more predominant during specific life ages.

IBMT did the experiment using two different groups of students. One group of students practiced the meditation and other student practices relaxation. Scientists used new technologies such as;

1. Physiological reaction in heart rate,

2. Respiratory amplitude and rate,

3. Skin conductance response (SCR),

4. Brain imaging,

The meditation group showed higher level of self-regulation than relaxation group. The anterior cingulate cortex (ACC) and prefrontal Cortex (PFC) of the brain show mechanism of 
self-regulation of attention and emotion. During the training, activity of the ACC and PFC increased more by meditation group than relaxation group.

The scientific experiment on meditation practices of Dr. Herbert Benson, associate professor of medicine at Harvard Medical School, and Dr. Jane Flemming explains very important information about "How a person's state of mind affects the body on a physical and genetic level." Research has described the negative effects of stress on the body. The stress release the stress-hormones such as adrenalin and cortisol. It raises the heart rate and blood pressure, weakens immunity and lowers fertility. The relaxation is linked to higher levels of feel-good chemicals such as serotonin and to the growth hormone which repairs cells and tissue, lowering heart rate, boosting immunity and strengthening the body.

Increased immunity - Researches at the Ohio State University found that meditation increased immunity in recovering cancer patients. When it practices daily, reduce the risk of breast cancer recurrence. A month of mediation exercises boost natural killer cells, and giving them resistance to tumors and to viruses.

Emotional balance - Meditation makes free of all the neurotic behavior that results from the existence of a tortured.

Increase memory and attention - A research at Massachusetts General Hospital found that parts of the brain's cerebral cortex which part of the brain deal with attention and memory were thicker.

Increase happiness - Scientists at the University of Wisconsin reported that people newly trained in meditation have shown an increase in electrical activity in the left frontal part of the brain, an area associated with positive emotion and happiness. The University of Wisconsin reported according to their researches Tibetan monk and molecular geneticist Matthieu Ricard is the happiest man. He is 66 years old. When he meditate on compassion his brain produces a level of gamma waves related to consciousness, attention, learning and memory never before reported in neuroscience.

Increased Fertility - A research at the University of Western Australia found that women are more likely to conceive during periods when they are relaxed rather than stressed.

Lowers the blood pressure - Harvard Medical School and British Medical Journal report that meditation lowered blood pressure by making the body less responsive to stress hormones.

Anti-inflammatory - The researchers at Emory University in the US say that Stress leads to inflammation, a state linked to heart disease, arthritis, asthma and skin conditions such as psoriasis, say meditation can help prevent and treat such symptoms.

Relives irritable bowel syndrome - The researchers at the State University of New York recommended meditation twice a day as an effective treatment to irritable bowel syndrome.

Reduce the physical pain, anxiety and stress - A study published in Psychotherapy and Psychosomatics showed sustained benefits over a three year period in a group of women who had taken an eight-week course in meditation. 
Helps lower blood sugar- Researchers at Cedars-Sinai Medical Center in Los Angeles showed that patients were able to lower their blood pressure, blood sugar and insulin by practicing meditation.

Brain and Meditation - The mind is immaterial. It is co-occurs and interrelated with material neural activity. What flows through the mind sculpts your brain. Main parts of the brain and its mechanism.

1. Prefrontal cortex - set goals, makes planes, directs actions, shapes emotions etc.

2. Anterior cingulate cortex (ACC) - steadies attention, helps integrate thinking and feeling

3. Insula - sense the internal state of the body (gut feeling etc.)

4. Thalamus - Station for sensory information

5. Brain stem - sends neuromodulators such as serotonin and dopamine.

6. Corpus callosum - passes information between two hemispheres

7. Cerebellum - regulates the movements

8. Limbic system - Central to emotion and motivation. It includes,

I. Hippocampus - forms new memories, detects threats

II. Hypothalamus - regulates primal drives such as hunger and sex, makes oxytocin, activates the pituitary gland.

III. Pituitary gland - triggers stress hormones, stores and releases oxytocin

Key Neurochemicals; when mind changes simultaneously brain also change. Major chemicals inside the brain that affect neural activity. Primary neurotransmitters

01 . Glutamate - excites receiving neurons

02. GABA (Gama amino-butyric acid) - inhibits receiving neurons

Neuromodulators (influence the neurotransmitters)

01. Serotonin - regulate mood, sleep, and digestion. Antidepressants increasing

02. Dopamine - involved with rewards and attention.

03. Norepinephrine - alerts and arouses

04. Acetylcholine - Promotes wakefulness and learning

\section{Neuropeptides}

01. Opioids - buffer stress, provide soothing, reduce pain, produce pleasure

02. Oxytocin - promotes nurturing behaviors toward children and bonding couples. Associate with blissful closeness and love.

03. Vasopressin - supports pair bonding. It may promote aggressiveness toward sexual rivals.

03. Cortisol - released by the adrenal glands during the stress response.

04. Estragen - affect libido, mood, and memory

Meditation is very important to restructure human brain. The left frontal lobe of the brain more developed of the meditators than others. The brain has two major divisions, right hemisphere and left hemisphere. Right hemisphere pertaining to intuitive imaging and left hemisphere pertaining to cognitive logical thinking.

If the person stuck on certain thoughts, he has a problem with the cingulate system. If trouble in focusing his attention, he has a problem in Prefrontal cortex prescription. If increase the anxiety, the problem is in basal ganglia system. If it is difficult to connect meaningfully with others, the problem is in the deep limbic system. If cannot tame the temper, the problem is in the temporal lobes. 


\section{CONCLUSION}

The neuropsychologist says, the mind is the mover and shaper of the mind. The brain and mind interact as unified system. The mind moves information through neuron system just as heart moves blood around the body. According to MRI's confirm that the mechanism of the brain intertwines with immune, cardiovascular, chronic illnesses, depression, anxiety and endocrine system and meditation can effect effectively to the brain to change the harmful processes of the brain. The Buddhist meditation mainly focus the development of the mind.

\section{References}

Dīgha Nikāya, Mahāsatipațțāna Sutta, BJTS, 2005

Majjhima Nikāya, Ānāpānasati Sutta, BJTS, 2005

Hanson, Rick. Buddha's Brain the Practical Neuroscience of Happiness, Love \& Wisdom. USA: New Harbinger Publications, Inc., 2009.

David J. Kalupahana, Buddhist Philosophy A Historical Analysis, Honolulu; The University Press of Hawaii, 1933 Grener K. Cristoper. Mindfulness and Psychotherapy, A division of Guilford Publication. 2005 